This item was submitted to Loughborough's Research Repository by the author.

Items in Figshare are protected by copyright, with all rights reserved, unless otherwise indicated.

\title{
The influence of tracking marker locations on three-dimensional wrist
}

\section{kinematics}

PLEASE CITE THE PUBLISHED VERSION

https://doi.org/10.1016/j.jsams.2020.03.011

PUBLISHER

Elsevier Ltd

VERSION

AM (Accepted Manuscript)

\section{PUBLISHER STATEMENT}

This paper was accepted for publication in the journal Journal of Science and Medicine in Sport and the definitive published version is available at https://doi.org/10.1016/j.jsams.2020.03.011.

LICENCE

CC BY-NC-ND 4.0

\section{REPOSITORY RECORD}

Turner, Josh, Steph Forrester, Aimee Mears, and Jonathan Roberts. 2020. "The Influence of Tracking Marker Locations on Three-dimensional Wrist Kinematics". Loughborough University.

https://hdl.handle.net/2134/12668459.v1. 


\title{
The influence of tracking marker locations on three-dimensional wrist kinematics
}

\author{
J. Turner, S.E. Forrester, A.C. Mears and J.R. Roberts. \\ Sports Technology Institute, Wolfson School of Mechanical, Electrical and Manufacturing Engineering, Loughbor- \\ ough University, Loughborough, Leicestershire, UK, LE11 3QF.
}

KEYWORDS wrist; biomechanics; upper extremity; movement; golf.

\begin{abstract}
Objectives: To determine the influence of tracking marker locations on wrist kinematics during free movements and the golf swing, with the intention of recommending a solution that generates meaningful three-dimensional wrist kinematics. Design: Repeated measures. Methods: Six participants performed free movements of flexion/extension, radial/ulnar deviation and forearm supination/pronation, with a further sixteen participants performing golf drives. A passive motion capture system tracked four different marker sets located on participants' hand and forearm segments. Variables of peak angle and range of motion were used to compare marker sets during free movements and angles at the top of the backswing and impact were compared during the golf swing. Results: Wrist marker set had a large $(\eta 2 \geq 0.557)$ and often significant ( $\mathrm{p} \leq \mathrm{0.051})$ effect on the variables measured during free movements, and a mixed $(\eta 2 \geq 0.108, \mathrm{p} \leq 0.198)$ effect on wrist angles during the golf swing. Wrist axial rotation range of motion during free forearm supination/pronation revealed the greatest difference between marker sets $\left(\sim 42^{\circ}\right)$. The large values generated by two of the marker sets for this rotation appeared to influence the values of flexion/extension and radial/ulnar deviation during the golf swing. Conclusions: The location of markers used to measure wrist kinematics can have a large effect on the angles generated. A solution of two markers located at the distal end of the forearm and one at the proximal, appears to minimise values of wrist axial rotation during free forearm supination/pronation and, consequently, produce more meaningful three-dimensional wrist kinematics.
\end{abstract}

\section{Practical Implications}

- The location of tracking markers used to measure wrist kinematics using passive motion capture can have a large effect on the angles generated.

- Tracking marker sets which have multiple markers located proximal to the distal end of the forearm can produce large ranges of wrist axial rotation during free forearm supination/pronation, which cannot be considered meaningful.

- During a three-dimensional movement, the large values of wrist axial rotation generated by these marker sets appeared to influence the values of flexion/extension and radial/ulnar deviation.

- Marker sets which track the forearm segment using two markers located at the distal end of this segment and one marker located at the proximal end, appear to produce more meaningful three-dimensional wrist kinematics.

-Wrist axial rotation angles should always be inspected to ensure that the marker set is producing suitable values. If no external forces are applied, values should be close to $\mathrm{o}^{\circ}$, although greater values may be possible in the presence of external forces.

\section{Introduction}

The kinematics of the wrist is useful to a range of applications, with clinicians using this data to support decision making ${ }^{1}$ and sports scientists, to determine how technique can improve performance ${ }^{2}$ or lead to injury. ${ }^{3}$ Motion of the wrist joint is considered to occur in two planes; sagittal (flexion/extension) and frontal (radial/ulnar deviation). Motion of the hand relative to the forearm in the transverse plane (wrist axial rotation) is expected to be negligible in magnitude 4,5 when no external forces are present. However, in the presence of external forces, larger magnitudes of wrist axial rotation appear possible, with studies reporting mean ranges of motion of $34.1^{\circ} 6$ and $42.0^{\circ}$.

In research, wrist motion is typically derived from passive motion capture systems which measure the three-dimensional $(3 \mathrm{D})$ position of markers located on hand and forearm segments. This process has been used to determine wrist kinematics during numerous movements, from activities of daily living 8,9 to higher velocity sporting movements, such as swinging a golf club $^{2,10,11}$ or tennis racket.3., 


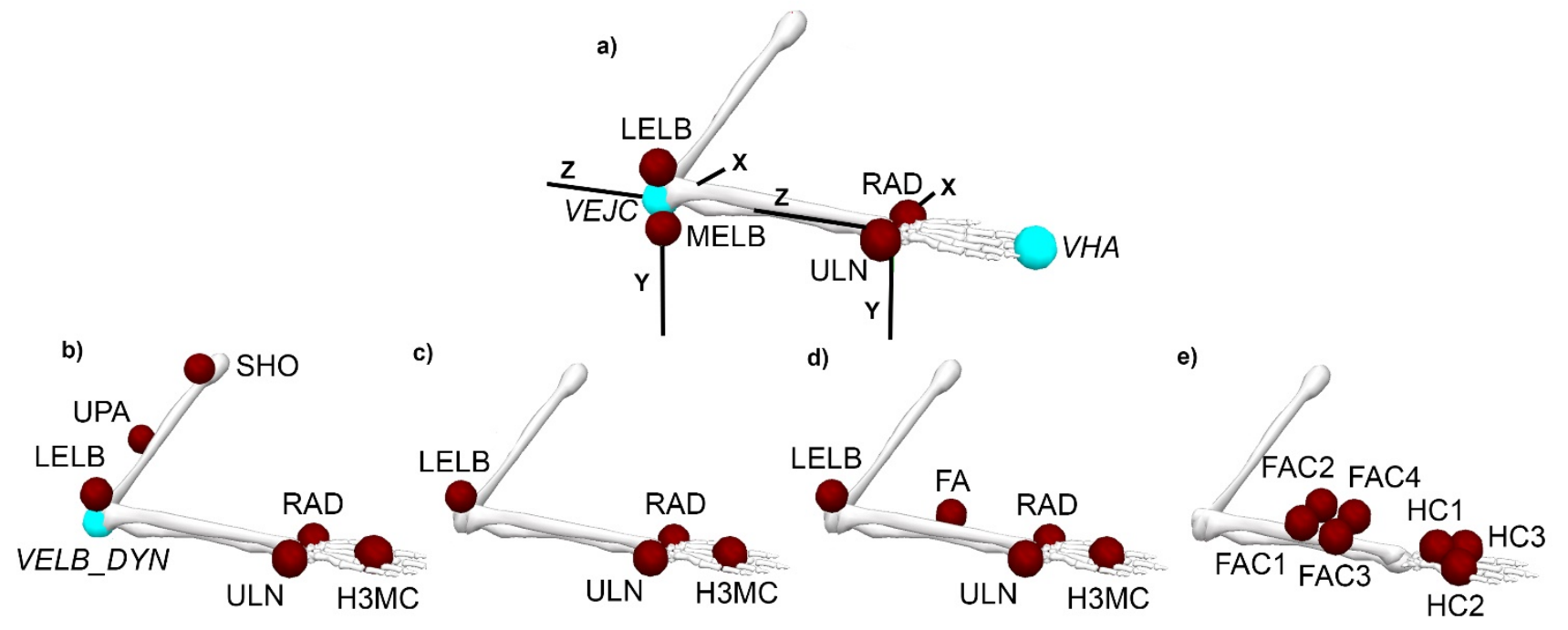

Figure 1. The wrist marker sets used in the study: a. segment defining markers and coordinate systems; b. market set 1 tracking markers; c. marker set 2 tracking markers; d. marker set 3 tracking markers; e. marker set 4 tracking markers. Red markers indicate physical markers, blue markers indicate virtual markers.

An issue arising from the abundance of studies reporting wrist kinematics using passive motion capture is the inherent variation in segment definition and marker locations, which will ultimately influence the kinematics reported and make between study comparisons difficult. A number of studies have compared the accuracy of their wrist kinematics to a benchmark system; however, none have presented accurate results about all three anatomical axes, with the values for wrist axial rotation either being too large $\left(>100^{\circ}\right)^{8}$ to be considered meaningful with respect to the physiological limits of the wrist joint, or neglected and not reported. ${ }^{13}$ Wrist axial rotation results were also neglected when comparing the angles generated by different upper extremity marker sets during functional movement tasks ${ }^{14}$ and, consequently, the influence of different tracking marker locations on $3 \mathrm{D}$ wrist kinematics also remains unclear. Therefore, the purpose of this study was to determine the influence of tracking marker locations on wrist kinematics during both free movements and a dynamic ${ }_{3} \mathrm{D}$ movement (golf swing), with the intention of recommending a solution that generates the most meaningful threedimensional wrist kinematics.

\section{Methods}

Two different sample groups were used for the two different protocols; free movements and dynamic golf swings. For the free movement analysis, six male participants (age 25.7 years \pm 2.9 years) with no previous wrist injuries that would affect range of motion (RoM) participated in the study. For dynamic golf swings, sixteen right-handed male golfers of varying ability (age $24.6 \pm 3.2$ years, handicap 16.5 \pm 8.6 strokes) participated. All participants gave informed consent to prior to the study, which was approved by Loughborough University Ethics Committee (approval number: G10-P8).
A newly developed marker set (marker set 1) and three wrist marker sets representative of those used in biomechanics research (marker set 2,3,4; references provided with the markers set descriptions below) were considered, resulting in fourteen passive retroreflective markers being attached to the participants hand, forearm and upper arm on their dominant writing side. Marker sets 1 to 3 were all skin-based and utilised the same three tracking markers locations on the hand segment; the radial and ulnar styloid processes and the head of the 3 rd metacarpal. For marker set 1 , the same two markers located on the radial and ulnar styloid process were used to track the forearm, along with a virtual elbow joint centre marker, reconstructed dynamically from the position of three markers located on the upper arm (lateral humeral epicondyle, mid-posterior and shoulder joint level) (Fig. 1b). For marker set 2, markers on the radial and ulnar styloid process and lateral humeral epicondyle were used to track the forearm 9, 15, 16 (Fig. 1c), whilst for marker set 3, an additional forearm tracking marker located approximately mid-way along the radial side of the forearm was used ${ }^{11,17}$ (Fig. 1d). Marker set 4 was comprised of two marker clusters, a triad located on the dorsal side of the hand and a four-marker cluster on the dorsal side of the forearm,2,14,18 with the markers mounted on a plastic backing plate. More detailed definitions of marker locations can be found in Appendix A.

The marker trajectories were tracked using a 12-Camera Vicon Nexus system (Oxford Metrics Ltd, Oxford, UK). For free movements the sampling frequency was set to $100 \mathrm{~Hz}$, however, this was increased to $500 \mathrm{~Hz}$ for dynamic golf swings. ${ }^{2,}$, 10 Prior to the movement trials, a static calibration trial was captured for each participant to create the local coordinate system for each segment. Participants stood with approximately $90^{\circ}$ shoulder abduction, $90^{\circ}$ elbow flexion and with the palmar aspect of the hand facing the floor with the wrist in a neutral position. ${ }^{19}$ 
a)
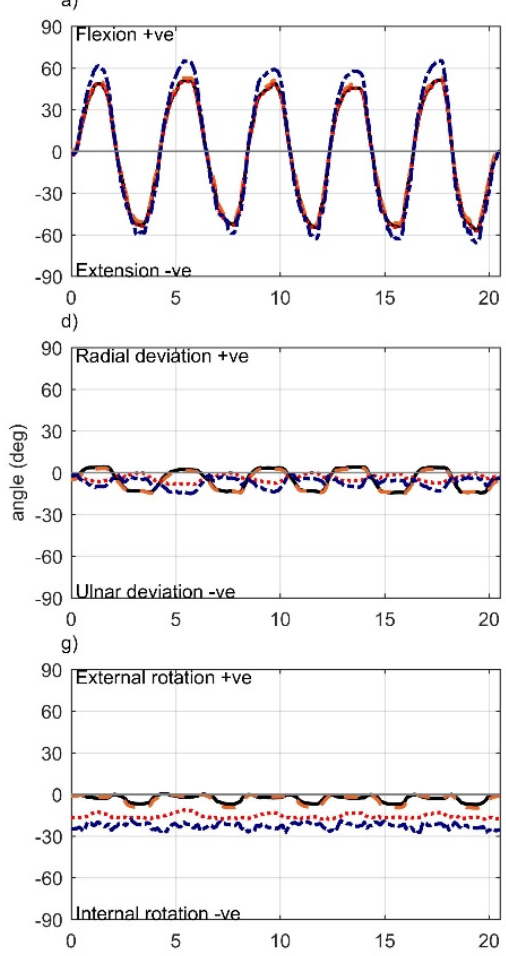

b)

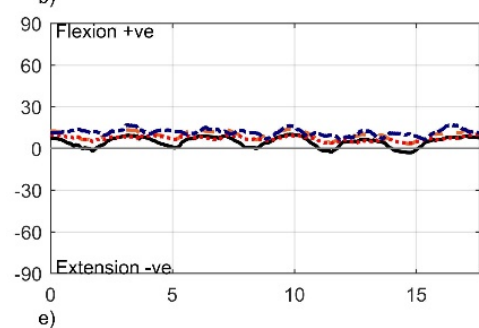

e)

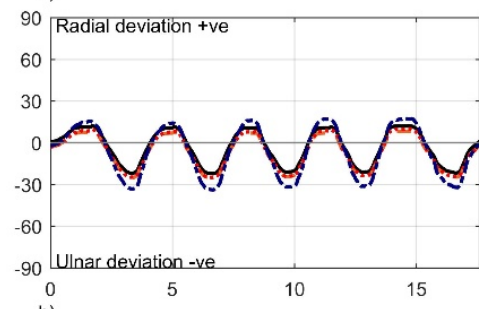

h)

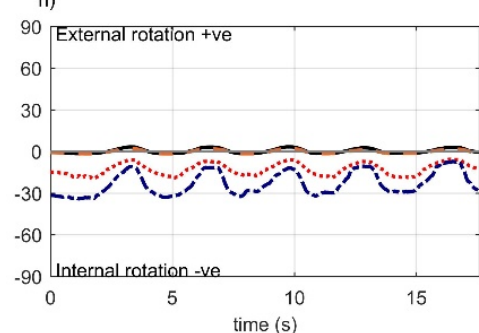

c)

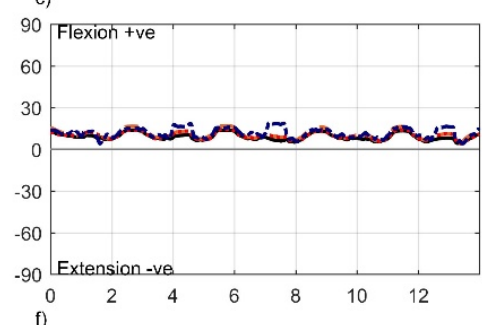

f)

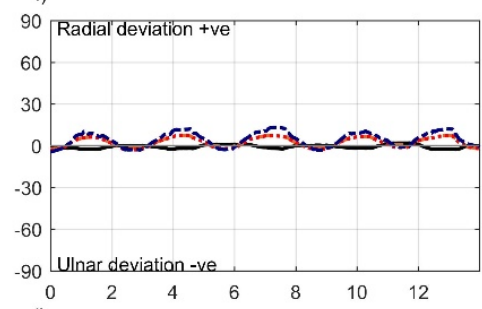

i)

90 External rotation +ve'

60

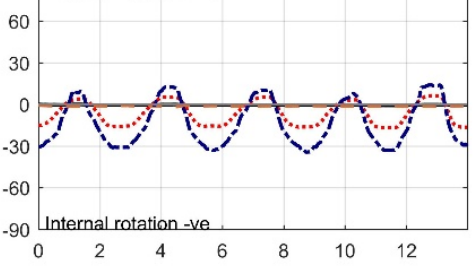

— Marker set 1 - - Marker set 2 …..... Marker set 3 ---- Marker set 4

Fig. 2. Wrist kinematics for a representative participant during free movements; flexion/extension during: a. flexion/extension; b. radial/ulnar deviation; c. forearm supination/pronation. Radial/Ulnar deviation during: d. flexion/extension; e. radial/ulnar deviation; f. forearm supination/pronation. Wrist axial rotation during: g. flexion/extension; h. radial/ulnar deviation; i. forearm supination/pronation.

The free movements consisted of five cycles of wrist flexion/extension, radial/ulnar deviation and forearm supination/pronation. Participants were sat at a desk with $90^{\circ}$ elbow flexion and instructed to keep the anterior aspect of their forearm in contact with the desk and stationary throughout each movement. During flexion/extension, participants placed their hands over the edge of the desk; during radial/ulnar deviation, participants held the palmar aspect of their hand in contact with the desk throughout the movement, thereby restricting unwanted flexion/extension. During forearm supination/pronation, participants started with the palmar aspect of their hand in contact with the desk and then rotated their forearms $90^{\circ}$ so their palms were perpendicular to the desk. ${ }^{8}$ The golf shots consisted of ten swings with the same driver $\left(10.5^{\circ}\right.$ loft, stiff-flex, $60 \mathrm{~g}$ shaft), whereby a subset of the five best quality shots were analysed, determined through impact location, subjective assessment of shot quality and minimal marker occlusion.

All four marker sets utilised the same forearm and hand segment coordinate systems (Fig. 1a), created in Visual ${ }_{3} \mathrm{D}$ (C-Motion, Germantown, USA). For the forearm, the frontal (XZ) plane of the segment was fit between the proximal (virtual elbow joint centre) and distal (radial and ulnar styloid process) segment endpoint markers, where the virtual elbow joint centre was the midpoint between the lateral and medial humeral epicondyles. The longitudinal
Z-axis of the segment was directed proximally from the distal segment endpoint to the proximal and lay in the frontal plane of the segment. The anteroposterior Y-axis of the segment was projected as the normal to the frontal plane in the anterior direction, with the $\mathrm{X}$-axis being calculated as the normal to the $\mathrm{YZ}$ plane. ${ }^{20}$ For the hand, the same procedure was followed with the frontal plane being determined from the radial and ulnar styloid process (proximal) and virtual hand (distal) markers. The virtual hand marker was created to scale the hand segment by projecting a marker distally along the longitudinal axis of the forearm, extending beyond the marker located on the head of the 3rd metacarpal, and to align both coordinate systems, ${ }^{10}$ replicating the neutral wrist position adopted by participants in the calibration trial.

For free movements, the marker trajectories were filtered using a 4th order zero-lag low pass Butterworth filter with a cut-off frequency of $6 \mathrm{~Hz}$, determined from residual analysis. ${ }^{21}$ Marker trajectories from the golf swing trials were filtered using an adaptive Butterworth filter ${ }^{22}$ with upper and lower cut-off frequency thresholds set to $10 \mathrm{~Hz}$ and $150 \mathrm{~Hz}$, respectively. Wrist joint angles were calculated as the rotation of the hand relative to the forearm using the six degree of freedom method ${ }^{23}$ and the XYZ Cardan rotation order. ${ }^{8,14,18}$ Rotation about the $\mathrm{X}$-axis represented flexion (+ve) and extension (-ve); Y-axis, radial deviation (+ve) and ulnar deviation (-ve) and Z-axis, wrist axial external (+ve) and internal rotation (-ve). 


\begin{tabular}{|c|c|c|c|c|c|c|c|}
\hline Movement & Variable $\left(^{\circ}\right)$ & $\begin{array}{l}\text { Marker } \\
\text { Set } 1\end{array}$ & $\begin{array}{l}\text { Marker } \\
\text { Set } 2\end{array}$ & $\begin{array}{l}\text { Marker } \\
\text { Set } 3\end{array}$ & $\begin{array}{c}\text { Marker } \\
\text { Set } 4\end{array}$ & $p, \eta^{2}$ & $\begin{array}{c}\text { Significant } \\
\text { pairwise } \\
\text { comparisons }\end{array}$ \\
\hline Wrist & Peak flexion & $49.7(6.0)$ & $54.1(5.9)$ & $49.9(6.7)$ & $56.2(10.2)$ & $0.051,0.557$ & \\
\hline Extension & RoM & $107.1(7.2)$ & $106.6(7.7)$ & $105.8(6.6)$ & $118.3(8.5)$ & $0.001,0.814$ & $c, e, f$ \\
\hline Wrist & Peak radial deviation & $11.0(3.6)$ & $7.5(3.9)$ & $9.4(3.5)$ & $17 \cdot 3(6.4)$ & $0.005,0.785$ & $a, e, f$ \\
\hline Radial/Ulnar & Peak ulnar deviation & $-19.8(2.0)$ & $-22.8(2.6)$ & $-21.6(2.9)$ & $-26.8(5.9)$ & $0.036,0.596$ & $\mathrm{a}$ \\
\hline Supination/ & Peak axial int. rotation & $-1.0(0.6)$ & $-1.8(0.7)$ & $-19.4(4.8)$ & $-35.2(12.7)$ & $0.001,0.895$ & $b, c, d, e, f$ \\
\hline Pronation & RoM & $0.8(0.4)$ & $1.2(0.6)$ & $23.4(2.7)$ & $42.6(6.9)$ & $0.000,0.975$ & $b, c, d, e, f$ \\
\hline $\begin{array}{l}\text { Key } \\
\text { Swing Event }\end{array}$ & Lead wrist $\left({ }^{\circ}\right)$ & $\begin{array}{c}\text { Marker } \\
\text { Set } 1\end{array}$ & $\begin{array}{l}\text { Marker } \\
\text { Set } 2\end{array}$ & $\begin{array}{c}\text { Marker } \\
\text { Set } 3\end{array}$ & $\begin{array}{c}\text { Marker } \\
\text { Set } 4\end{array}$ & $\mathrm{p}, \eta^{2}$ & $\begin{array}{l}\text { Significant } \\
\text { pairwise } \\
\text { comparisons }\end{array}$ \\
\hline \multirow[t]{4}{*}{ Impact } & Flexion/Extension & $-2.4(10.9)$ & $-2.4(11.6)$ & $-5.8(11.3)$ & $0.3(17.4)$ & $0.164,0.122$ & \multirow{3}{*}{$a, b, c, e, f$} \\
\hline & Radial/Ulnar deviation & $-32.3(10.1)$ & $-36.4(9.7)$ & $-35.6(10.1)$ & $-43.6(11.2)$ & $0.000,0.842$ & \\
\hline & Wrist axial rotation & $-0.3(2.8)$ & $-2.3(3.9)$ & $-7.6(9.2)$ & $-7.1(22.4)$ & $0.188,0.112$ & \\
\hline & Trail wrist $\left(^{\circ}\right)$ & & & & & & \\
\hline Top of & Flexion/Extension & $-63.7(8.4)$ & $-64.4(8.7)$ & $-65.5(8.5)$ & $-68.4(8.1)$ & $0.000,0.551$ & \multirow{4}{*}{$\begin{array}{c}\text { b, c, d, e, f } \\
a, b, c, d, e, f \\
\quad a, b, c, d\end{array}$} \\
\hline \multirow[t]{2}{*}{ Backswing } & Radial/Ulnar deviation & $-21.0(9.2)$ & $-22.6(9.4)$ & $-14.6(8.0)$ & $-7.7(12.3)$ & $0.000,0.570$ & \\
\hline & Wrist axial rotation & $-3 \cdot 3(5.6)$ & $-7.6(7.4)$ & $-10.3(8.9)$ & $-14.9(16.2)$ & $0.002,0.452$ & \\
\hline \multirow[t]{3}{*}{ Impact } & Flexion/Extension & $-9.8(9.8)$ & $-10.1(9.9)$ & $-10.4(9.5)$ & $-5.9(12.6)$ & $0.098,0.166$ & \\
\hline & Radial/Ulnar deviation & $-29.6(7.5)$ & $-30.2(8.1)$ & $-30.8(7.0)$ & $-41.9(9.3)$ & $0.000,0.810$ & \multirow[t]{2}{*}{$c, e, f$} \\
\hline & Wrist axial rotation & $-1.6(2.0)$ & $-2.4(2.3)$ & $-2.4(8.1)$ & $3.0(15.8)$ & $0.198,0.108$ & \\
\hline
\end{tabular}

Table 1 Key wrist angles (group mean (SD)) during both free movements and the golf swing, along with the statistical main effect p-value and effect size $\left(\eta^{2}\right)$. Post-hoc significant pairwise differences $(\mathrm{p}<0.05)$ : a. marker set $1 \mathrm{v}$ marker set 2 ; b. marker set $1 \mathrm{v}$ marker set 3; c. marker set $1 \mathrm{v}$ marker set 4 ; d. marker set $2 \mathrm{v}$ marker set 3; e. marker set $2 \mathrm{v}$ marker set 4; f. marker set $3 \mathrm{v}$ marker set 4 .

The main effect of wrist marker set on the peak magnitude and RoM of wrist angles during the free movements and angles at the top of the backswing and impact during the golf swing (both lead and trail wrists) was assessed using a one-way ANOVA with repeated measures. Effect sizes were determined using partial eta squared $\left(\eta^{2}\right)$ with values of o.01, 0.06 and 0.14 representing small, medium and large effects respectively. ${ }^{24}$ Prior to the ANOVA tests, the data was assessed for normality (Sharipo-Wilk test) and sphericity (Mauchly's test) with a Greenhouse-Giesser correction being applied when the sphericity assumption was violated. For statistically significant ANOVA results, pairwise comparisons to explore the main effect of wrist marker set were further conducted with a Bonferroni correction to reduce the chance of a Type 1 error. Statistical analysis was conducted using SPSS v23.o (SPSS, Inc., Chicago, USA) with the alpha probability set to 0.05 .

\section{Results}

The main effect of marker set was consistently large $\left(\eta^{2} \geq 0.557\right)$ and typically significant $(p \leq 0.051)$ for the variables measured during the free movements (Fig. 2 and Table 1). The greatest difference between marker sets was ob- served for wrist axial rotation RoM during forearm supination/pronation (Fig. 2i). Marker sets 3 and 4 generated unrealistically large mean wrist axial rotation RoM values during this movement $\left(23.8^{\circ}\right.$ and $44.2^{\circ}$, respectively) given that no external forces were applied, whereas marker sets 1 and 2 generated more meaningfully small RoM values for this rotation $\left(0.8^{\circ}\right.$ and $1.2^{\circ}$, respectively). Additionally, marker set 4 generated significantly larger ranges of motion for flexion/extension and radial/ulnar deviation when these were the primary movements being performed (Fig. $2 \mathrm{a}$ and $2 \mathrm{e}$ ). The flexion/extension and radial/ulnar deviation RoM values were in good agreement for marker sets 13 ( $\leq 1.3^{\circ}$ average difference), although there was a small but consistent offset in the peak magnitude of these angles (Table 1). The results of flexion/extension, radial/ulnar deviation and axial rotation when these were not the primary movements being performed (Fig. 2, graphs off the main diagonal), typically had distinct angular cycles present in the data despite this movement not being consciously performed.

During the golf swing, the choice of marker set had a mixed ( $p \leq 0.198)$ but typically large effect $\left(\eta^{2} \geq 0.108\right)$ on wrist angles. As with the free movements, the values of wrist axial rotation for marker sets 1 and 2 were smaller 
than marker sets 3 and 4 (Table 1). Across all marker sets, the magnitude of wrist axial rotation was typically greater at the top of the backswing compared to impact, whilst for marker sets 1 and 2, the values of wrist axial were typically greater during the golf swing compared to the free movements. When the magnitude of axial rotation was greatest (lead wrist, top of the backswing), poorer agreement between the marker sets for the results of flexion/extension and radial/ulnar deviation was observed (Table 1). Conversely, when the magnitude of axial rotation was small relative to the other rotations (e.g. trail wrist radial/ulnar deviation at impact), the results between marker sets for this rotation were in better agreement with those observed during the free movements (Table 1 ).

\section{Discussion}

The measurement of wrist kinematics is important for a range of applications, yet the influence of tracking marker locations on $3 \mathrm{D}$ wrist kinematics and a marker set that generates meaningful kinematics about all three anatomical axes has yet to be presented in research. The results of this study suggest that the choice of tracking marker locations can have a large and significant effect on the wrist kinematics generated about all three anatomical axes. During free movements, the greatest difference between marker sets occurred for wrist axial rotation during forearm supination/pronation, where two of the marker sets (marker sets 3 and 4) generated large values of wrist axial rotation, which cannot be considered meaningful as no external forces were present during this movement. Furthermore, when applied to the golf swing, the large values of wrist axial rotation generated by these marker sets ( 3 and 4 ) appeared to influence the results of flexion/extension and radial/ulnar deviation. A solution of two markers located distally and one marker located proximally along the forearm segment (marker sets 1 and 2) produced suitably small values of wrist axial rotation during free forearm supination/pronation and, therefore, appears to generate more meaningful $3 \mathrm{D}$ wrist kinematics.

Both marker sets 3 and 4 used multiple markers located proximal to the distal end of the forearm to track the rotation of the forearm segment. The large wrist axial rotation results during free forearm supination/pronation suggest that these marker locations were less effective at tracking the axial rotation of the forearm. This finding aligns with previous research, where decreased forearm supination/pronation RoM has been reported when using marker sets with multiple markers located proximal to the distal end of the forearm. ${ }^{14,18,25}$ The authors in these studies attributed the decreased forearm RoM to soft tissue artefact, ${ }^{18,25}$ a known limitation of marker-based motion capture, ${ }^{26}$ commenting that during forearm supination/pronation, the forearm skin rotates less in more proximal regions compared to distal regions of the forearm. It appears likely that this was also the reason for the increased wrist axial rotation values generated by marker sets 3 and 4 in this study.

During the golf swing, the large values of wrist axial rotation generated by marker sets 3 and 4 appeared to influ- ence the values of flexion/extension and radial/ulnar deviation (Table 1). The nature of this influence is not clear, however, could be a consequence of the type of crosstalk demonstrated by Sinclair et al., ${ }^{27}$ whereby a dominant rotation influences the values of the rotations of lesser magnitude. This theory is suggested as it appears that when the results of flexion/extension or radial/ulnar deviation were relatively large compared to axial rotation, the results follow the expectation set from the free movements. However, when the values for these two rotations were of similar or lesser magnitude to axial rotation, the agreement between marker sets was noticeably poorer (Table 1). Crosstalk was also evident during the free movements; however, this type of crosstalk could exist for several other reasons, including small misalignments in the axes of rotation ${ }^{8,18}$ or participants not performing a pure rotation about each axis.

As the golf club exerts forces on the golfer via the hands during the golf swing, there is a possibility that greater magnitudes of wrist axial rotation could have been passively induced during this movement, ${ }^{6,7}$ compared to the forearm supination/pronation free movement. The tendency for a small increase in the values of wrist axial rotation generated by marker sets 1 and 2 during the golf swing supports this notion, although this could also have been the result of crosstalk. Large magnitudes of wrist axial rotation (up to $25^{\circ}$ ) have previously been reported during the golf swing, ${ }^{28}$ with the authors considering this to be genuine passive rotation as a result of the forces applied by the golf club. However, the results were obtained with a marker set comparable to marker set 4. Based on the results of this study, such a conclusion appears questionable, with the marker set utilised likely to have influenced the values reported.

Whilst this study has demonstrated the influence of tracking marker location on $3 \mathrm{D}$ wrist kinematics, there is still a lack of understanding of the fundamental accuracy of the angles generated by the marker sets as no gold standard comparative was used in this investigation. This, in part, is due to there being no universally agreed gold standard measurement to compare passive marker-based motion capture against. ${ }^{29}$ Goniometers have previously been used to validate results from passive motion capture; ${ }^{1,8}$ however, this measurement technique can produce inaccurate results. ${ }^{1}$ Alternatively, passive motion capture results have been compared to those obtained from $\mathrm{x}$-ray imaging techniques, ${ }^{1,13}$ although these methods are not widely available or accessible. The Cardan rotation order was controlled in this study; however, the choice of rotation order has previously been shown to have a large influence on the kinematics generated. ${ }^{27}$ Further work is therefore required to understand the most appropriate Cardan rotation order to use when determining wrist kinematics during different movements.

\section{Conclusion}

The choice of marker locations used to track the hand and forearm segments can have a large effect on wrist kinematics. The greatest difference between marker sets dur- 
ing free movements occurred for wrist axial rotation during forearm supination/pronation, whereby two of the marker sets, typical of those used in a number of research studies, produced ranges of motion that cannot be considered meaningful $\left(23.4^{\circ}\right.$ and $42.6^{\circ}$, respectively) as no external forces were applied during this movement. Furthermore, when used to measure wrist angles during the golf swing, the large magnitudes of wrist axial rotation generated by these marker sets appeared to compromise the results for flexion/extension and radial/ulnar deviation. Wrist marker sets which track the forearm using two distally located and one proximally located marker produced more meaningful ranges of wrist axial rotation during forearm supination/pronation $\left(\leq 1.2^{\circ}\right)$ and, consequently, values of flexion/extension and radial/ulnar deviation during the golf swing. The use of this tracking marker set to measure wrist kinematics during free and dynamic movements is encouraged, although the choice of Cardan rotation order needs to be carefully considered.

\section{ACKNOWLEDGMENT}

The lead author is supported by an EPSRC grant, issued by Loughborough University. The authors would like to thank all participants who volunteered for this study.

\section{REFERENCES}

1. Hillstrom H, Garg R, Kraszewski A et al. Development of an Anatomical Wrist Joint Coordinate System to Quantify Motion During Functional Tasks. J App Biomech 2014; 30(4):586-593. https://doi.org/10.1123/jab.2011-0094

2. Joyce $C$, Burnett $A$, Cochrane J et al. A preliminary investigation of trunk and wrist kinematics when using drivers with different shaft properties. Sport Biomech 2016; 15(1):61-75. https://doi.org/10.1080/14763141.2015.1123764

3. Glynn J, Kentel B, King M et al. Comparison of wrist angular kinematics and forearm EMG data for an elite, intermediate and novice standard tennis player performing a one-handed backhand groundstroke. Int J Sports Sci Eng 2007; 1:157-164.

4. Ryu J, Cooney W, Askew L et al. Functional ranges of motion of the wrist joint. J Hand Surg 1991; 16(3):409-419. https://doi.org/10.1016/0363-5023(91)gooo6-W

5. Taylor C, Schwarz R. The anatomy and mechanics of the human hand. Artificial Limbs 1955; 2(2):22-35.

6. Gupta A, Moosawi N. How much can the carpus rotate axially? An in vivo study. Clin Biomech 2005; 20(2):172-176. https://doi.org/10.1016/j.clinbiomech.2004.09.014

7. Roux J, Micallef J, Rabischong P et al. Study of the transmission of pronation-supination movements in the wrist. Ann Chir Main Memb Super 1996; 15(3):167-180.

https://doi.org/10.1016/So753-9053(96)80006-8

8. Murgia A, Kyberd P, Chappell $\mathrm{P}$ et al. Marker placement to describe the wrist movements during activities of daily living in cyclical tasks. Clin Biomech 2004; 19(3):248-254. https://doi.org/10.1016/j.clinbiomech.2003.11.012

9. Rosen J, Perry J, Manning $\mathrm{N}$ et al. The human arm kinematics and dynamics during daily activities - toward a 7DOF upper limb powered exoskeleton. In: The 12th International Conference on Advanced Robotics: IEEE; 2005.

https://doi.org/10.1109/ICAR.2005.1507460

10. Betzler N. The effect of differing shaft dynamics on the biomechanics of the golf swing. Dissertation, Edinburgh Napier University; 2010.

11. Smith A. Coach informed biomechanical analysis of the golf swing. Dissertation, Loughborough University; 2013.
12. Whiteside D, Elliott B, Lay B et al. The effect of racquet swing weight on serve kinematics in elite adolescent female tennis players. J Sci Med Sport 2014; 17(1):124-128.

https://doi.org/10.1016/i.jsams.2013.03.001

13. Small C, Bryant J, Dwosh I et al. Validation of a 3 D optoelectronic motion analysis system for the wrist joint. Clin Biomech 1996; 11(8):481-483. http://dx.doi.org/10.1016/So268-0033(96)00042-3

14. Boser Q, Valevicius, A, Lavoie E et al. Cluster-based upper body marker models for three-dimensional kinematic analysis: comparison with an anatomical model and reliability analysis. J Biomech 2018; 72:228-234. https://doi.org/10.1016/i.jbiomech.2018.02.028

15. Aguinaldo A, Buttermore J, Chambers H. Effects of Upper Trunk Rotation on Shoulder Joint Torque among Baseball Pitchers of Various Levels. J Appl Biomech 2007; 23(1):42-51. https://doi.org/10.1123/jab.23.1.42

16. Choi A, Lee J, Mun J. Ground reaction forces predicted by using artificial neural network during asymmetric movements. Int. J Precis Eng Man 2013; 14(3):475-483. https://doi.org/10.1007/s12541-013-0064-4

17. Strifling K, Lu N, Wang $\mathrm{M}$ et al. Comparison of upper extremity kinematics in children with spastic diplegic cerebral palsy using anterior and posterior walkers. Gait Posture 2008; 28(3):412419. https://doi.org/10.1016/j.gaitpost.2008.01.018

18. Schmidt R, Disselhorst-Klug C, Silny J et al. A marker-based measurement procedure for unconstrained wrist and elbow motions. J Biomech 1999;32(6):615-621. https://doi.org/10.1016/Soo219290(99)00036-6

19. Norkin C, White D. Measurement of joint motion: A guide to goniometry, 3rd ed., F.A Davis Company, 2003

20. C-motion.com. Constructing the Segment Coordinate System - Visual3D Wiki Documentation. Available at: https://www.cmotion.com/v3dwiki/index.php?title=Constructing the Segment Coordinate System\&oldid $=15614$. Accessed 26 June 2019.

21. Winter D. Biomechanics and motor control of human movement, 4th ed., New Jersey, John Wiley \& Sons, 2009

22. Erer K. Adaptive usage of the Butterworth digital filter. J Biomech 2007; 40(13):2934-2943. https://doi.org/10.1016/j.jbiomech.2007.02.019

23. Spoor C, Veldpaus F. Rigid body motion calculated from spatial co-ordinates of markers. J Biomech 1980; 13(4):391-393. https://doi.org/10.1016/0021-9290(80)90020-2

24. Cohen J. Statistical Power Analysis for the Behavioural Sciences, 2nd ed., Lawrence Erlbaum Associates, 1988

25. Wang W, Wang D, Wesseling M et al. Comparison of modelling and tracking methods for analysing elbow and forearm kinematics. Proceedings of the Institution of Mechanical Engineers, Part H: Journal of Engineering in Medicine 2019; 223(11):1113-1121. https://doi.org/10.1177\%2Fo954411919872400

26. Cappozzo A, Catani F, Leardini A et al. Position and orientation in space of bones during movement: experimental artefacts. Clin Biomech 1996; 11(2):90-100.

https://doi.org/10.1016/0268-0033(95)00046-1

27. Sinclair J, Taylor P, Edmundson C et al. Influence of the helical and six available Cardan sequences on ${ }_{3} \mathrm{D}$ ankle joint kinematic parameters. Sport Biomech 2012; 11(3):430-437. https://doi.org/10.1080/14763141.2012.656762

28. Carson H, Richards J, Mazuquin B. Examining the influence of grip type on wrist and club head kinematics during the golf swing: benefits of a local co-ordinate system. Eur J Sport Sci 2019; 19(3):327-335. https://doi.org/10.1080/17461391.2018.1508504

29. Wells D, Alderson J, Middleton K et al. The repeatability of upper limb models: anatomical landmarks vs. cluster/functional marker sets. In: XXIV Congress of the International Society of Biomechanics; 2013. 


\section{APPENDIX A}

Table A.1 Detailed definitions of marker locations used in the investigation, adapted from Smith, $2013^{11}$.

\begin{tabular}{|c|c|c|}
\hline Marker & Location & Description \\
\hline $\mathrm{SHO}$ & Upper arm & Lateral side of upper arm at shoulder joint centre level \\
\hline UPA & Upper arm & Mid posterior upper arm \\
\hline LELB & Upper arm & Lateral humeral epicondyle \\
\hline MELB & Upper arm & Medial humeral epicondyle \\
\hline VELB* & Elbow & Midpoint of lateral and medial humeral epicondyles \\
\hline VELB_DYN* & Elbow & $\begin{array}{l}\text { Midpoint of lateral and medial humeral epicondyles, reconstructed dynamically from the po- } \\
\text { sition of the LELB, UPA and SHO markers }\end{array}$ \\
\hline $\mathrm{FAC}_{1}$ & Forearm & $\begin{array}{l}\text { The proximal and lateral marker of the forearm cluster when stood in the calibration trial ori- } \\
\text { entation }\end{array}$ \\
\hline $\mathrm{FAC}_{2}$ & Forearm & $\begin{array}{l}\text { The proximal and medial marker of the forearm cluster when stood in the calibration trial } \\
\text { orientation }\end{array}$ \\
\hline $\mathrm{FAC}_{3}$ & Forearm & $\begin{array}{l}\text { The distal and lateral marker of the forearm cluster when stood in the calibration trial orien- } \\
\text { tation }\end{array}$ \\
\hline $\mathrm{FAC}_{4}$ & Forearm & $\begin{array}{l}\text { The distal and medial marker of the forearm cluster when stood in the calibration trial orien- } \\
\text { tation }\end{array}$ \\
\hline FA & Forearm & Mid-way along the length of forearm on the radial side \\
\hline RAD & Radius & Radial styloid process \\
\hline ULN & Ulnar & Ulnar styloid process \\
\hline $\mathrm{HC}_{1}$ & Hand & The proximal marker of the hand cluster when stood in the calibration trial orientation \\
\hline $\mathrm{HC}_{2}$ & Hand & The distal and lateral marker of the hand cluster when stood in the calibration trial orientation \\
\hline $\mathrm{HC}_{3}$ & Hand & The distal and medial marker of the hand cluster when stood in the calibration trial orientation \\
\hline $\mathrm{H}_{3} \mathrm{MC}$ & Hand & Head of the $3^{\text {rd }}$ metacarpal \\
\hline $\mathrm{VHA}^{*}$ & Hand & Distal to the head of the $3^{\text {rd }}$ metacarpal, projected onto the long axis of the forearm \\
\hline
\end{tabular}

* Virtual marker

\section{APPENDIX B}

Supplementary material related to this article can be found, in the online version, at doi: https://doi.org/10.1016/j.jsams.2020.03.011 